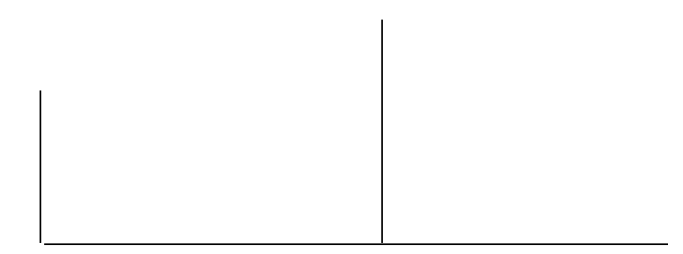

Rev. Latinoam. Psicopat. Fund., VI, 2, 26-35

\title{
Ser mulher dói: relato de um caso clínico de dor crônica vinculada à construção da identidade feminina
}

Josiane Bocchi, Paola Salinas,

Ricardo Gorayeb

\begin{abstract}
O presente artigo apresenta um caso clínico de dor crônica atendido no Ambulatório de Psicologia Médica do HCFMRP-USP e discute o alcance da linguagem sobre o corpo, a presença de aspectos inconscientes na formação de sintomas físicos e a relação entre queixa somática e história afetiva. Propõe uma reflexão sobre a inter-relação entre os domínios médico e psicológico.
\end{abstract}

Palavras-chave: Psicologia médica, dor crônica,

psicossomática, hospital geral, psicanálise 
Este artigo descreve uma intervenção realizada no Ambulatório de Psicologia Médica do Hospital das Clínicas da Faculdade de Medicina de Ribeirão Preto. $O$ trabalho neste ambulatório circunscreve a situação hospitalar ao mesmo tempo que a ultrapassa. $\mathrm{O}$ atendimento psicológico abarca casos com dificuldades afetivas relacionadas a tratamento médico, a procedimentos específicos e à presença de patologia orgânica. Engloba ainda casos com manifestações corporais de aspectos psicológicos, não necessariamente correlatos à patologia médica.

A relação entre transtornos somáticos e variáveis psicológicas pode ocorrer de diversas formas, seja porque os fatores psicológicos interferem no tratamento do problema médico, comprometendo a adesão; seja porque provocam respostas fisiológicas que precipitam ou exacerbam os sintomas físicos. Ou ainda, o próprio estilo de vida constitui-se em risco adicional à saúde do indivíduo. Autores observam que em determinadas afecções dermatológicas os traços de personalidade, o modo de reagir ao estresse e o estilo de vida, podem afetar a enfermidade ou a adesão às recomendações médicas, assim como a presença de estressores psicossociais, desajustamento interpessoal e baixa autoestima. Outros sugerem que estímulos emocionais estão relacionados à formação da úlcera duodenal através de respostas fisiológicas, como aumento das concentrações de ácido e pepsina (Folks \& Kinney, 2000).

Partindo do estudo de Jacques Lacan (1960) e de seu axioma: o inconsciente é estruturado como uma linguagem, entendemos o indivíduo e seu corpo inseridos no registro simbólico. A palavra humaniza o corpo orgânico e dá ao homem a característica de humano. Assim, o sujeito está atrelado ao seu discurso, tanto no que diz como enunciado quanto no que traz como enunciação: no que diz e no que "diz a mais", nas possibilidades de mal-entendido. Tomando este referencial, tudo que diz respeito ao humano sai do registro do instinto e passa a localizar-se no registro da linguagem. Todas as questões, inclusive do orgânico, passam a ter relação com o simbólico estruturado pela aquisição da linguagem. A analogia entre inconsciente e linguagem remete tanto ao caráter 


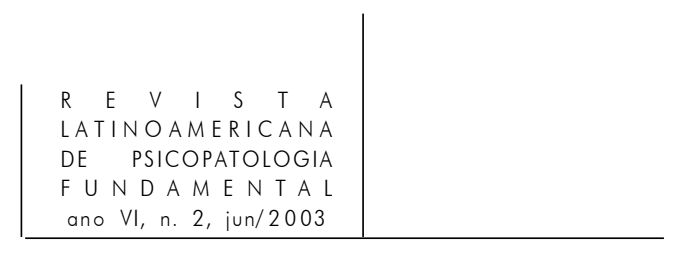

fundador da palavra no domínio inconsciente, quanto seu emprego como método terapêutico. Em Sigmund Freud (1915), o processo de tornar um conteúdo consciente é sempre mediado pela palavra, inversamente, a quebra dessa associação determina a perda da consciência.

$\mathrm{Na}$ concepção lacaniana, o inconsciente é estruturado por relações entre significantes, por sobreposições e deslizes entre eles. Jacques Lacan parte dos conceitos freudianos de condensação e deslocamento para formular os processos de metáfora e metonímia, respectivamente. Tais processos organizam o funcionamento simbólico dos significantes no inconsciente. O termo significante é retirado da lingüística e por ele trabalhado, em relação à estruturação subjetiva, articulando-se como interpretação do sujeito acerca do seu ser. O inconsciente emerge como uma estrutura de linguagem na qual o indivíduo está inserido, sendo por ela determinado à medida que efeitos do inconsciente se fazem presentes em sua vida e em manifestações somáticas específicas. Neste sentido o corpo subjetivado e entrecortado pela linguagem exprime, de forma figurada e indireta, representações inconscientes. A libido desligada da representação recalcada transforma-se em fenômeno corporal (dor localizada, paralisia).

A chamada lesão psicossomática entra neste contexto à medida que for influenciável pelo discurso de cada sujeito e pelas modificações subjetivas alcançadas em determinadas situações. A incidência da manifestação psicossomática no corpo é vista como palavra escrita, não necessariamente solidária a uma cadeia de sentidos. Ou seja, como a inscrição de um signo, que se satisfaz em si mesmo sem ser endereçado a um outro, como num discurso ou queixa.

Ao verificar que o aspecto psicológico interfere inclusive na bioquímica de determinado órgão, reafirmamos o corpo físico também como um corpo simbólico. Tal concepção supera a compreensão do órgão e de seu funcionamento apenas como um aparato biológico e, em determinados casos, supera a própria motivação do indivíduo, no sentido de que a pulsão corre à revelia deste.

Sigmund Freud (1905) define pulsão como um conceito limítrofe entre o somático e o psíquico. Consiste em uma força oriunda de fontes corporais, que impõe ao organismo um constante afluxo de excitação do qual o indivíduo não pode fugir. Com efeito, o fator quantitativo presente na conceituação de pulsão coloca um indivíduo exposto a esta força que emerge do interior do corpo, de início indeterminada, mas que sempre conhece um destino psíquico (Laplanche \& Pontalis, 2001).

Trata-se de uma incidência no soma do saber inconsciente, de determinações psíquicas que escapam ao sujeito, saber parasita que se torna patógeno e lesa o próprio corpo (Fux, 2001). Sendo assim, a psicologia é um dos campos de conhecimento mais influentes no saber médico, à medida que 


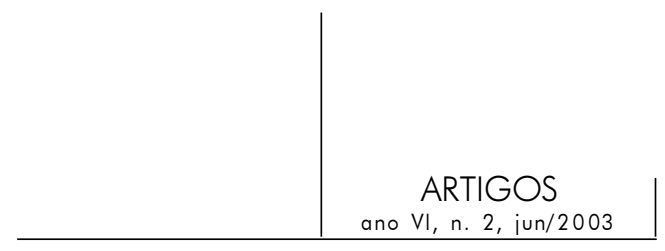

marca a existência de um sujeito por trás do órgão, e que especifica todo o alcance da subjetividade sobre o corpo. "Para Lacan o organismo ultrapassa os limites do corpo, o organismo inclui o corpo e a libido, como um órgão extracorpóreo que o circunda" (p. 23). O organismo é o somatório do órgão e do investimento libidinal (pulsional) feito neste órgão. Tal investimento pode deslocar-se desde as zonas erógenas até um superinvestimento na imagem corporal ou determinado órgão de choque.

A seguir, a apresentação e discussão de um caso clínico objetiva exemplificar a construção de um sintoma físico alicerçado na história afetiva da paciente. Apontaremos aspectos que escapam à compreensão da paciente, mas que se mostram logicamente encadeados em seu discurso e na sua história. Será descrito todo o percurso de atendimento, desde a triagem até a intervenção propriamente dita. A paciente, do sexo feminino, tem 35 anos, casada, três filhos, evangélica e trabalha como diarista. Foi encaminhada pelo setor de Ginecologia do HCFMRP-USP, com o relato de importante disfunção sexual e queixas vulvares crônicas. As hipóteses diagnósticas em seu prontuário médico eram: dor pélvica crônica, dor crônica retovaginal e dor neuropática. Já no início da investigação médica, uma doença sexualmente transmissível foi diagnosticada. Como a dor se manteve mesmo após a resolução deste problema e nenhum outro achado médico compatível com a sintomatologia apresentada foi encontrado, a equipe formulou a hipótese de uma etiologia psicológica.

Foram realizadas quatro sessões de triagem, para o esclarecimento diagnóstico e indicação de tratamento. A entrevista abrangeu a descrição e investigação da queixa em seus aspectos afetivos, funcionais e somáticos, além do exame psicológico.

A queixa inicial foi dor no canal da urina quase diariamente e ardência vaginal há três anos, acentuadas após a relação sexual. Referiu dificuldades sexuais, relacionadas à dor e também a problemas conjugais, que culminaram com a ausência de lubrificação vaginal: "Só posso ter relação quando meu corpo pode".

O problema manteve-se sem explicação médica e tratamento eficaz, apesar da diversidade de especialidades consultadas (urologia, ginecologia e clínica da dor). Após concluir "baterias de exames" ouviu dos profissionais que seu problema seria de fundo psicológico. Disse não ver ligação entre o problema físico e aspectos emocionais, por isso relutou em procurar atendimento psicológico, quando sugerido, desde as primeiras investigações médicas. Ainda, não estava certa "se é psicológico ou não".

Informa que o inicio da dor, há três anos, coincidiu com a descoberta da infidelidade do marido. Corrige-se em seguida, a dor começara há dois anos, deixando escapar neste ato falho a verdadeira relação causal que estabeleceu. Ao constatar que o marido mantivera vários casos extraconjugais, desenvolveu uma 


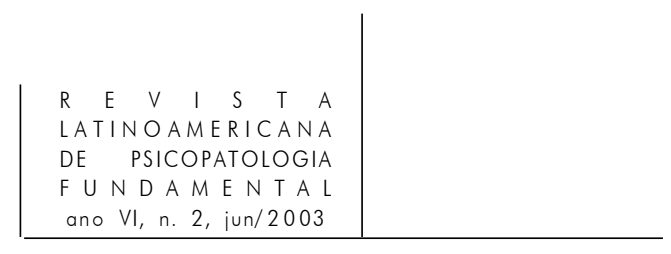

sintomatologia depressiva (insônia, perda de peso e choro constante). Evoluiu para um quadro de descontrole impulsivo, com três tentativas de suicídio: atirando-se de um veículo em movimento, por enforcamento e intoxicação medicamentosa. Todas evitadas pelos familiares, sobretudo pelo marido. As três tentativas mantêm como traço comum a presença do marido, sendo, em última instância, endereçadas ao seu olhar.

Neste período, realizou atendimento psiquiátrico e psicológico, fez uso de lorazepan e amitriptilina e realizou terapia familiar durante seis meses. Interrompeu o seguimento, afirmando ter decidido resolver seu problema sozinha. Obtivera melhora do quadro depressivo, contudo, o sintoma de dor surgiu em seguida.

À época da triagem, apresentava uma autopercepção vinculada aos cuidados médicos, queria trabalhar no hospital como voluntária e fazer um curso técnico de enfermagem. Ainda fazia uso de amitriptilina, indicado agora também como tratamento para dor. $\mathrm{O}$ acompanhamento psiquiátrico era realizado trimestralmente.

O marido envolvera-se sexualmente com homossexuais, prostitutas e pessoas que a paciente conhecia. Embora isto a fizesse sofrer, pediu que the contasse tudo com riqueza de detalhes. Diz: "Achei que era a única mulher da vida dele, me entreguei de cabeça para ele. Me sentia supersegura”. Não conseguia compreender a traição do marido, já que ele mesmo lhe dissera que é ótima em todos os aspectos, como mãe, como mulher ( sic). Ressaltou ter sido muito companheira, ajudando-o inclusive em "serviços de homem" (dirigir seu caminhão, trocar pneu). Era uma mulher completa, "trabalhando como um homem" e ao mesmo tempo, "fogosa", com grande desejo sexual. A traição veio colocar em xeque esta identidade de mulher completa. Em seu relato destacouse um primeiro significante, que amarra sua posição subjetiva: "macho-fêmea". A mãe assim lhe chamava, questionando sua feminilidade.

A triagem teve como eixo oferecer um espaço de elaboração das queixas permitindo um reposicionamento quanto ao sofrimento psicológico. Objetivou uma modificação na posição inicial de não saber se há relação entre a dor física e a psíquica. Neste processo, foi marcante o questionamento sobre o ser mulher suficiente para o marido, acompanhado de referências à sua mãe, que não lhe teria ensinado questões relativas à feminilidade. Concluiu-se a triagem com diagnóstico psicanalítico de neurose histérica e diagnóstico psicológico de transtorno doloroso somatoforme persistente. Como conduta, indicou-se psicoterapia.

A paciente poderia iniciar o tratamento em grupo ou aguardar pelo atendimento individual. Optando pelo grupo, afirmou: “... já demorei muito para procurar a psicologia". Assim, o tempo de escuta que recebeu pareceu ter seu primeiro efeito: demandar atendimento psicológico, num giro do enunciado inicial 


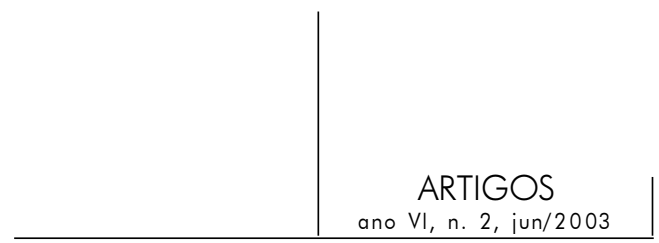

“não sei se é psicológico ou não”. A oferta de um espaço de fala ao sujeito no momento em que este procura por atendimento psicológico pode favorecer o processo de implicação subjetiva, pois ouvi-lo aí pode torná-lo mais responsável por sua demanda. $\mathrm{O}$ acolhimento inicial na triagem contribui também para o esclarecimento da real demanda de cada sujeito, permitindo uma verificação de sua posição frente à queixa enunciada (Salinas \& Santos, 2002). Entendemos que a eficácia de um tratamento vincula-se também a uma demanda bem construída.

Mais do que um levantamento sistemático de informações, a triagem no Ambulatório de Psicologia Médica visa formular questões, prefigurando um caráter interventivo, à medida que disponibiliza ao sujeito a oportunidade de decidir ingressar ou não no tratamento ofertado.

O grupo caracterizou um primeiro tratamento, com duração de seis meses. A paciente manteve uma postura participativa e implicada, centrando seu relato nas dificuldades conjugais, na infidelidade e na constatação da sua insuficiência como mulher, já que o marido "precisou" de outros envolvimentos. Disse que seu problema era "de berço". Começa a listar queixas em relação à sua mãe, esta teria lesado seu desenvolvimento, impedindo brincadeiras infantis e interferindo na vivência da "mocidade" e da feminilidade, dificultando a paquera e o contato com garotas da mesma idade. Concluiu que a mãe a teria "bloqueado". Este significante foi marcado, uma vez que o tratamento que realizava no Ambulatório da Dor era denominado "bloqueio". Na sessão seguinte concluiu: "Eu me causei esta dor”. Indagada sobre isso, falou novamente de sua mãe. Referiu que teria sido conduzida por esta exclusivamente aos trabalhos domésticos como resposta à questão da feminilidade: "Ela queria que eu aprendesse a cuidar de uma casa. Uma mulher tinha que saber fazer isto”. Queixa-se da parcialidade da resposta materna. Questionada sobre o que teria faltado, ainda não articulava a questão do feminino (ter sido bloqueada/mulher pela metade) e a sexualidade (ser macho-fêmea/mulher toda), ambas relacionadas à queixa de que sua mãe não lhe teria ensinado a ser mulher suficiente para um homem.

Ao fim do grupo as queixas correspondiam explicitamente à área sexual e à "falha materna". Descreveu-se como "boba", inexperiente sexualmente, chegando a dizer que a mãe, por sua vez, também era “boba” e não sabia ser mulher. Ao término do grupo mantinha a dor, embora com menor freqüência. Obteve uma melhora na qualidade das relações sexuais, da funcionalidade, retomando inclusive seu trabalho, "melhora do emocional”, redução da ansiedade e incremento do bem estar. Indicou-se psicoterapia individual, visando um aprofundamento das questões analisadas no grupo.

Após um intervalo de dois meses, ao ingressar nesse novo trabalho, tinha remissão completa da dor, mantendo apenas a ardência vaginal após as relações 


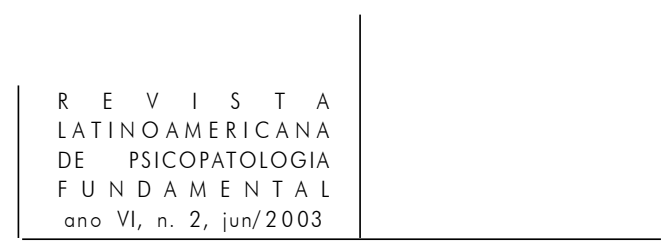

sexuais. Retomou questões abordadas no trabalho grupal, reafirmando: "Eu fui mandada pela minha mãe". O aceitar ser "mandada" não deixa de ter vinculação com a sexualidade, pois acreditava que fazendo tudo que o marido "mandava" iria ser a mulher que ele queria. Não lhe negava nada, pensando ser assim uma "supermulher, a única mulher". Desejava completá-lo e reciprocamente, que ele a preenchesse em seu vazio: "Não sei se é porque eu era rejeitada, a doidinha". Há aqui nova referencia à mãe, que além de "macho-fêmea" a chamava de "doida".

Esta escolha de tudo dar ao outro remete a uma posição de gozo ${ }^{1}$ embasada na crença da mulher toda, que veio a ruir com a revelação da infidelidade. Sua identidade feminina fora colocada em questão e, a partir daí, tomada no registro da insuficiência. Ela se vê como alguém que viveu para fazer pelos outros.

Por outro lado, denigre a figura masculina, criticando o marido, que não teria "retribuído" a tudo que ela lhe proporcionou como esposa e como mãe. Ele teria faltado como companheiro em momentos importantes, foi "роисо" e também "fraco de sexo". Em contrapartida, era completa e "fogosa", tudo o que supunha que ele queria. Frente à família, conduzia e resolvia os problemas de saúde de todos, colocando-se como imprescindível. Na triagem isso apareceu relacionado ao interesse por ingressar no hospital como enfermeira.

Tal postura assinala o lugar ocupado pela paciente como resposta à demanda suposta do Outro (Autre), cujos efeitos sobre sua vida se fazem presentes em suas escolhas e expectativas. Ela é a que nunca diz não, tanto na família como no casamento. Em uma perspectiva psicanalítica, o papel do Outro (Jacques Lacan, 1949, 1960, 1998) tem especial destaque na estruturação psíquica, repercutindo na maneira como o sujeito se percebe. Da relação primordial com as figuras parentais emerge, de um lado, o Outro materno (relação dual inicial) e, de outro, o Outro paterno (como um terceiro) que intervirá nesta relação. A partir desse processo, o indivíduo interpreta sua verdade subjetiva, ou seja, o lugar que acredita ocupar nesta estruturação (Silvestre, 1986). Vemos neste caso que a resposta dada é mostrar-se toda, evitando evidenciar a falta no Outro, preocupando-se em evitar que o desejo ou a necessidade se coloquem.

Encaminharemos a discussão do caso para o âmbito da psicologia clínica hospitalar e sua interface com os campos de saberes médico e psicanalítico. Verificamos a interdependência destes domínios à medida que determinadas lesões, ao conjugarem sofrimento psíquico e corporal, evocam pontos de intersecção entre estas áreas.

1. Refere-se ao desejo inconsciente. Esta noção ultrapassa qualquer consideração sobre afetos, emoções e sentimentos e coloca a relação com o objeto atrelada aos significantes inconscientes. 


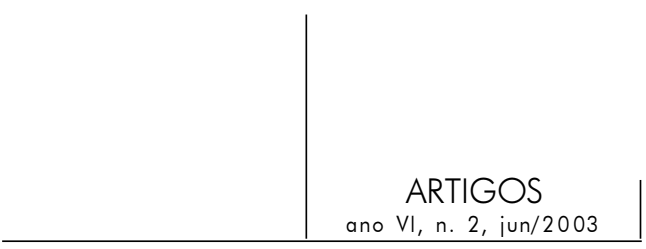

Na perspectiva lacaniana, ao falarmos em efeito patógeno ou terapêutico da linguagem no corpo, à medida que o inconsciente se estrutura como linguagem, não haveriam doenças psicossomáticas, mas sujeitos com lesões psicossomáticas, como um modo singular de resposta de cada sujeito. Na lesão psicossomática, a libido está corporificada, contrariando a visão psicologizante do sujeito, que pressupõe que este teria controle sob a manifestação psicossomática, podendo alterá-la com sua mudança de humor ou mesmo por meio de uma intenção consciente.

Embora hajam divergências neste campo, há objetivos comuns como priorizar um modelo assistencial voltado para o paciente em vez do trabalho centrado na doença (Martins, 1992).

Observamos na prática clínica determinadas afecções em que os sintomas corporais mantêm afinidade com significações recortadas no discurso do sujeito, evocando para sua compreensão uma concepção simbólica de corpo, como uma potência expressiva, dotada da capacidade de transpor conflitos psíquicos para o plano somático. Assim, reforçamos que a posição subjetiva pode se inscrever no corpo de diversas formas, sem que haja um conceito fixo para nomeá-la. Ainda que haja necessidade de nos situarmos quanto ao respaldo orgânico e etiológico de um transtorno, há que se considerar o uso que o sujeito faz dessa afecção real (Gallano, 1996).

No caso descrito, a dor aparece como conseqüência de um conflito psíquico associado à feminilidade, marcando uma suposta incompetência como mulher conseqüente, do ponto de vista da paciente, da "má formação" que recebeu de sua mãe. Um evento da realidade - traição do marido - vem confirmar essa auto-percepção: a mulher que por algum motivo falhou na tentativa de ser seu objeto de desejo absoluto.

A posição de tudo querer completar no Outro não está relacionada somente à questão sexual ou amorosa, mas é, antes de tudo, um modo particular de resposta do sujeito às demandas da vida, colocando-se sempre pronta a suprir qualquer falta. Mantém esse comportamento em relação à família de origem, ao marido e aos filhos, ao mesmo tempo que sofre e se queixa desse abuso (sic). Termina por ocupar-se na vida em "não deixar faltar", pensando assim responder ao que se espera de uma mulher, ao mesmo tempo que amortece sua própria falta. Não sabe ela que esta falha é estrutural na vida psíquica, posto que em algum momento nos deparamos com a castração. Não é possível ser toda e colocar-se como um tampão para o Outro em todas as relações que estabelecer.

Entendemos que a psicanálise na condução de um caso, cuja psicopatologia implica o fenômeno corporal - neste caso, a dor física - interroga a distinção entre transtornos orgânicos e psicológicos. O uso subjetivo da dor não indi- 
ca necessariamente sua causa, mas aponta para a singularidade do sujeito em questão (Soler, 1996). É necessário estar apto a lidar com as consequiências desta singularidade.

Pretendemos também salientar a importância da intervenção psicológica no hospital geral, colocando em evidência sua atualidade face à emergência de uma gama de fenômenos cuja ausência de resposta ao tratamento médico convencional evidencia a amplitude da relação entre o orgânico e o psíquico.

O encaminhamento para o Ambulatório de Psicologia surge como uma consequiência, impondo-se a necessidade de um olhar - ou melhor, uma escuta - à particularidade do caso. Assim, os dois campos de saber - médico e psicológico - caminhariam paralelamente não fossem os momentos de intersecção entre eles, como é ilustrado no caso apresentado neste artigo.

\section{Referências}

Folks, D. G. \& Kinney, F. C. Condições dermatológicas. In: Stoudemire, A. (Org.). Fatores psicológicos afetando condições médicas. Porto Alegre: Artmed, 2000, p. 127-42.

FreUd, S. (1894). Las neuropsicosis de defensa. In: Obras completas. Buenos Aires: Amorrortu, 1988, p. 41-68. v. 3.

(1915). Lo inconciente. In: Obras completas. Op. cit, p. 153-214.

(1915). Pulsiones y destino de pulsíon. In: Obras completas. Op. cit, p. 109224. v. 14

(1905). Tres ensayos de teoria sexual. In: Obras completas. Op. cit, p. 109-224. v. 7.

Fux, S. Psicossomática: uma questão para a psicanálise. Correio. Revista da Escola Brasileira de Psicanálise, n. 35, p. 18-27, 2001.

Gallano, C. La histérica y el rechazo del cuerpo en las enfermedades graves. In: Gorali, V. (Org.). Psicoanálisis y Medicina. Atuel, 1996, p. 15-26.

LACAN, J. (1960). A instância da letra no inconsciente ou a razão desde Freud. In: Escritos. Rio de Janeiro: Jorge Zahar, 1998, p. 496-533.

(1949). O estádio do espelho como formador da função do eu. In: Escritos, op. cit., p. 96-103.

(1960). Subversão do sujeito e a dialética do desejo no inconsciente freudiano. In: Escritos, op. cit., p. 807-42.

Laplanche, J. \& Pontalis, J.-B. Vocabulário da psicanálise. 4. ed. São Paulo: Martins Fontes, 2001.

Martins, L. A. N. Interconsulta hoje. In: Mello Filho, J. Psicossomática hoje. Porto Alegre: Artes Médicas, 1992, p. 160-4. 


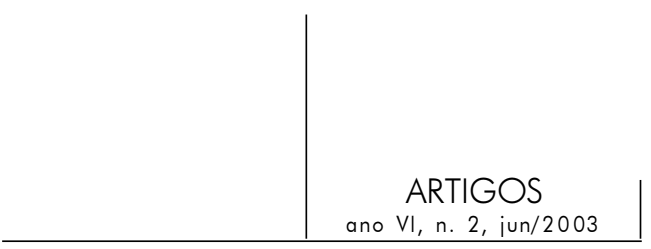

Salinas, P.; SAntos, M. Serviço de triagem em clínica-escola de psicologia: a escuta analítica em contexto institucional. Psychê. Universidade São Marcos, São Paulo, ano VI, n. 9, 2002.

Silvestre, M. O cálculo da clínica. Clínica Lacaniana, n. 2, p. 35-50, 1986.

Soler, C. Descartes con Freud. In: Gorali, V. (Org.) Psicoanálisis y medicina. Atuel, 1996 , p. 73-8.

\section{Resumos}

En este artículo se presenta un caso clínico de dolor crónico atendido en el Ambulatorio de Psicología Médica del HCFMRP-USP y se discute el alcance del lenguaje sobre el cuerpo, la presencia de aspectos inconscientes en la formación de síntomas físicos y la relación entre las quejas somáticas y la historia afectiva. Se propone una reflexión sobre la interrelación que hay entre los campos médico y psicológico.

Palabras clave: Psicologia médica, dolor crónico, psicosomática, hospital general, psicoanálisis

Les auteurs rapportent une observation clinique de douleur chronique évaluée à la consultation de Psychologie Médicale du HCFMRPUSP et discutent la portée du langage sur le corps, la présence des aspects inconscients dans la formation des symptômes physiques et la relation entre plainte somatique et histoire affective. La possibilité d'une reflexion sur l'inter-relation entre les domaines médicaux et psychologiques, est abordée.

Mots clés: Psychologie Médicale, douleur chronique, psychosomatique, Hôpital général, psychanalyse

This article presents a clinical case of chronic pain treated at the Out-Patient Clinic in Psychology of the University of São Paulo Hospital. It discusses the effect of language on the body, the presence of unconscious aspects in the formation of physical symptoms, and the relationship between the patient's somatic complaints and affective history. It suggests a reflection on the interrelationship which exists between the domains of medicine and of psychology.

Key words: Medical psychology, chronic pain, psychosomatics, general hospital, psychoanalysis 